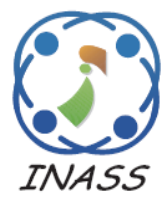

\title{
Adaptive Backstepping Controller Design Based MPPT of the Single-Phase Grid- Connected PV System
}

\author{
Rafika El idrissi $^{1 *} \quad$ Ahmed Abbou $^{1} \quad$ Mohcine Mokhlis $^{1} \quad$ Mahdi Salimi $^{2,3}$ \\ ${ }^{I}$ Electrical Engineering Department, Mohammadia School of Engineers, \\ Mohammed V University in Rabat, Morocco \\ ${ }^{2}$ Power Electronics, Machines, and Control Group, \\ Nottingham University, Nottingham NG7 2RD, United Kingdom \\ ${ }^{3}$ Department of Engineering, Ardabil Branch, Islamic Azad University, Iran \\ * Corresponding author's Email: rafika.elidrissi@gmail.com
}

\begin{abstract}
The environmental condition changes lead to obvious fluctuation in photovoltaic panels' output power. Therefore, to make efficient use of photovoltaic (PV) systems the maximum power point tracking (MPPT) controllers are required. Many classical methods are proposed to track the MPP, but they will lead to a high power drop when rapid changes in the atmospheric conditions occur, which necessities a robust controller with high performance. In such a manner, the proposed controller is designed for this purpose. There are two stages of the proposed controller: The artificial neural network (ANN) based the first stage that generates the PV panel optimal voltage and the second phase consists of a non-linear adaptive backstepping control, which is able to follow this optimum voltage by acting on the DC/DC boost converter's duty cycle. The input-output linearization technique is based the suggested controller. The last is robust and safe from the parameters fluctuation, load variation, and the atmospheric condition changes. In the proposed control design, unknown and estimated converter parameters are assumed, especially the inductor and input capacitor, considering an adequate Lyapunov function. A single-phase inverter connects the boost converter to the grid. However, for this connection to be made the power factor should be unified and the inverter current should be synchronized with the grid voltage. The sliding mode controller (SMC) is designed to operate on the inverter duty cycle for the resolution of these tasks. The controller is used to enhance the robustness and the system's rapidity. Besides, the DC bus is regulated using the proportional and integral (PI) controller. Matlab/Simulink software is used to simulate the overall system. Furthermore, for accurate results, the proposed controller is compared with perturb \& observe (P\&O), ANN-backstepping sliding mode (ANN-BSMC), and ANN-backstepping integral sliding mode (ANN-BISMC) techniques. The findings show that the proposed method outweighs other methods in terms of tracking rapidity, steady-state error and the fluctuations around the MPP under severe assumptions.
\end{abstract}

Keywords: Adaptive backstepping controller, MPPT, Single-phase grid-connected PV system, ANN, sliding mode controller.

\section{Introduction}

Nowadays the technology has been developed and the fossil fuels have been decreased, hence the $\mathrm{PV}$ panels become an important issue in all over the world. The researchers have been motivated to develop them and improve their energy production because, as known, they are clean, inexpensive, and easy to be installed [1-3]. However the PV systems depend on environmental factors and the loadimposed operating point [4]. Several MPPT approaches have been used in PV systems with the intent of enhancing the performance of PV panels. These MPPT techniques are used to transfer maximum power from the PV source to the load or grid via the action on the converter's duty cycle under weather condition changes. It should be noted that in the literature, there are substantial studies regarding MPPT techniques. Complex MPPT algorithms are 


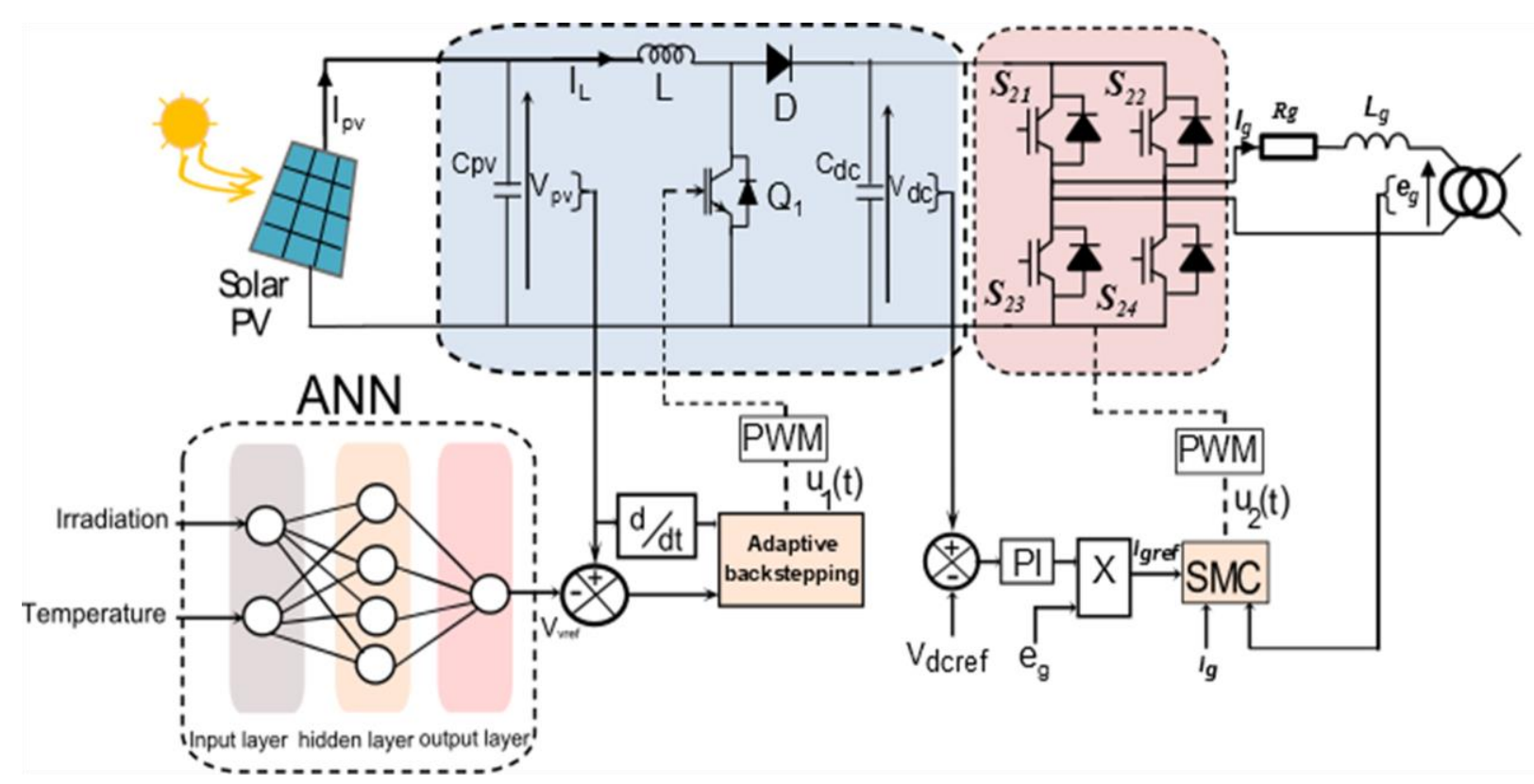

Figure. 1 Configuration of the entire system

known as direct methods among these reports. These methods include the well-known perturb\& observe (P\&O) [5-7] and the incremental conductance (IC) [8] algorithms that are the most used. They are easy to be implemented and they recognize intuitively. However, they suffer from oscillation around the MPP and they cannot handle the environmental changes.

Artificial intelligent methods, including the fuzzy logic (FL) [9, 10], artificial neural network (ANN) [11-13], particle swarm optimization (PSO) [14], are also considered to mitigate the drawbacks of the previous methods. They have better performance outcomes and tend to be extremely superior to MPP tracking because, regardless of the abrupt weather changes, they are able to achieve full power easily and without any oscillation around the MPP. However, most of these techniques are costly and complicated in the implementation.

In addition to the above methods, recent papers have been interested to MPPT-based voltage and MPPT-based current [15]. Those methods are either the current-based MPPT algorithm together with current controller or the voltage-based MPPT algorithm together with the voltage controller. These hybrid strategies are suggested to overcome individual inconveniences of the direct approaches and provide high convergence speed and low oscillations across the MPP. The non-linear relation between the PV voltage and solar irradiation found the MPPT-based voltage to be efficient. However, the reliability of this method depends on the voltage controller principle.
Typically, a basic PI controller executes the voltage regulator [16], the implementation of this controller provides slow response with significant overshoot and considerable steady state error. In [17], backstepping control is considered to improve the voltage regulation, which enhances the MPP tracking. However, this controller suffers from steady state error without satisfying the robustness against the external disturbances. Furthermore, the sliding mode controller was designed in [18]. This method experiences a chattering phenomenon. Moreover, the authors are designed an improved method to increase the MPPT speed and accuracy, however oscillations are observed.

In this paper, an innovative way to boost PV behaviour and to obtain robust performances against the weather condition changes and external disturbances with fast MPPT. Where, the ANN is used to generate the PV optimal voltage and the nonlinear adaptive backstepping control is used to track this optimal voltage by operating on the duty cycle of the boost converter, using its average state equations. The regulation technique consists of the linearization of input-outputs with undefined parameters. In this control, the converter parameters are assumed unknown and estimated, which is the main contribution in this work $[19,20]$. The proposed controller performances are compared with the $\mathrm{P} \& \mathrm{O}$ and the ANN-BSMC techniques.

A single-phase inverter connects the PV system to the grid. In this case, the DC link voltage should be regulated, hence the PI controller is used. In addition, the output current must be matched with the grid 
voltage to supply the grid with electricity, so to achieve this task the sliding mode controller is candidate.

The paper is organized in the following steps: Section 2 recommends an overall system design, Section 3 offers the system modelling; the proposed controller is designed in sections 4 and 5, sections 6 and 7 respectively discuss the results of the simulation and the conclusion.

\section{The overall system configuration:}

As seen in Fig. 1, the total configuration is comprised of a 3-series PV panel of connected SM55 type models and a boost converter DC/DC and gridconnected single-phase inverter. To achieve the MPP of this PV panel, the solar irradiation and temperature are sensed and given to an off-line ANN block to generate the PV panel optimal voltage that is regulated using the adaptive nonlinear backstepping controller. The controller creates a signal input control to enforce the boost converter to track the optimal voltage. The inverter is regulated by the DC bus adjustment and synchronization of grid current and voltage to incorporate the electrical power into the grid.

\section{The system modelling:}

\subsection{The PV module modelling:}

$$
\begin{gathered}
I_{p}=I_{p h}-I_{o}\left[\exp \left(\frac{q\left(V_{p}+R_{s} I_{p}\right)}{\gamma N K T}\right)-1\right] \\
-\frac{V_{p}+R_{s} I_{p}}{R_{s h}}
\end{gathered}
$$

Where:

$$
\begin{gathered}
I_{o}=I_{o r}\left(\frac{T}{T_{r}}\right)^{3} \exp \left(\frac{q E_{g}}{K \gamma}\left[\frac{1}{T_{r}}-\frac{1}{T}\right]\right) \\
I_{o r}=\frac{I_{s c r}}{\exp \left(\frac{q V_{o c}}{N K \gamma T}\right)-1} \\
I_{p h}=\left[I_{s c r}+K_{i}\left(T-T_{r}\right)\right] \frac{E}{1000}
\end{gathered}
$$

With:

$I_{p}[\mathrm{~A}], V_{p}[\mathrm{~V}]:$ The PV module output current and voltage.

$N_{p}, N_{s}$ : The number of cells connected in parallel and series.

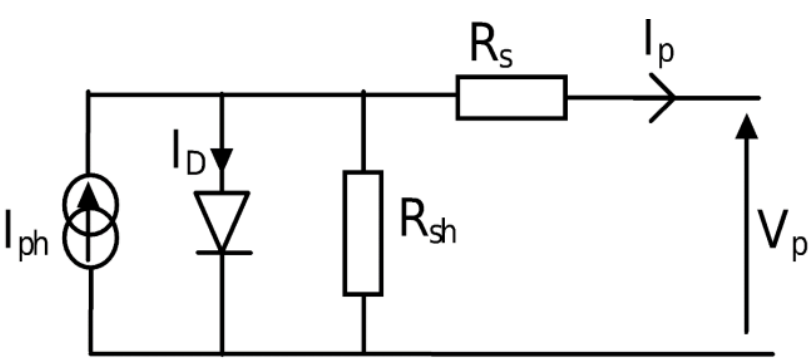

Figure. 2 The general PV model of electrical circuit

q: The charge of electron equals to $1.6 \times 10-19$ [C].

$\mathrm{K}$ : Boltzmann constant equals to $1.3805 \times 10^{-23} \mathrm{~J} / \mathrm{K}$. $\gamma$ : The ideality factor of $p-n$ junction.

$\mathrm{T}[\mathrm{K}], \mathrm{E}[\mathrm{W} / \mathrm{m} 2]$ : The cell temperature and the sun radiation.

$E_{g}$ : The cell energy in the semiconductor range equals to $1.1[\mathrm{eV}]$.

$T_{r}[\mathrm{~K}]$ : The nominal cell temperature.

$I_{o r}, I_{o}$ : The cell saturation current at $T_{r}$ and the cell saturation current of the cell.

$I_{\text {scr }}$ [A]: The cell short-circuit current at $T_{r}$.

$K_{i}[\mathrm{~A} / \mathrm{K}]:$ The short circuit current temperature coefficient equal to $4 \times 10^{-4}$.

$\mathrm{E}\left[\mathrm{W} / \mathrm{m}^{2}\right]$ : the sun radiation.

Rs, Rsh: the series and shunt resistances.

The value of $R_{s}=0$ and $R_{s h}=\infty$ are considered neglected to simplify the analysis. In terms of simplicity, the PV model mathematical equation used in the simulation is as follows:

$$
I_{p}=I_{p h}-I_{o}\left[\exp \left(\frac{q V_{p}}{\gamma N K T}\right)-1\right]
$$

The PV modules are connected in series and in parallel, creating a PV array to provide the power needed. The PV array represented by the following equation:

$$
\begin{gathered}
I_{p}=N_{p} I_{p h}-N_{p} I_{o}\left[\exp \left(\frac{q V_{p}}{\gamma N N_{s} K T}\right)\right. \\
-1]
\end{gathered}
$$

The energy transferred to the load can be affected by the radiation and temperature changes. This can be observed from the power-voltage (P-V) PV model characteristics as shown in Fig. 3. Therefore, the PV 
Table 1. the proposed PV model (shell SM55) characteristics

\begin{tabular}{|l|l|}
\hline Parameters' name & Values \\
\hline $\mathrm{P}_{\max }$ & 55 \\
\hline $\mathrm{V}_{\text {oc }}(\mathrm{V})$ & 21.7 \\
\hline $\mathrm{I}_{\mathrm{sc}}(\mathrm{A})$ & 3.45 \\
\hline $\mathrm{V}_{\max }$ & 17.4 \\
\hline $\mathrm{I}_{\max }$ & 3.15 \\
\hline $\mathrm{N}$ & 36 \\
\hline$N_{s}$ & 3 \\
\hline
\end{tabular}

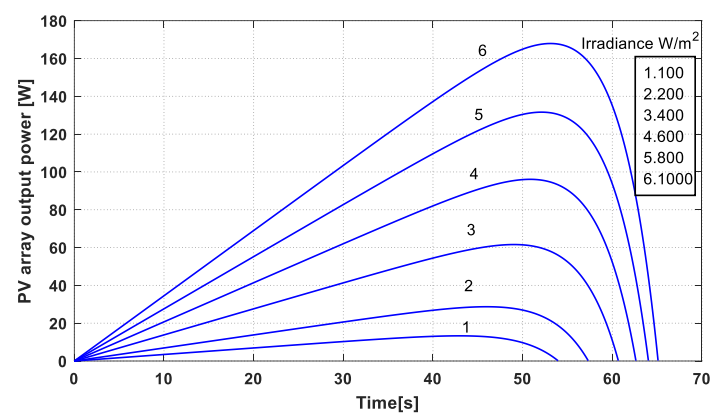

(a)

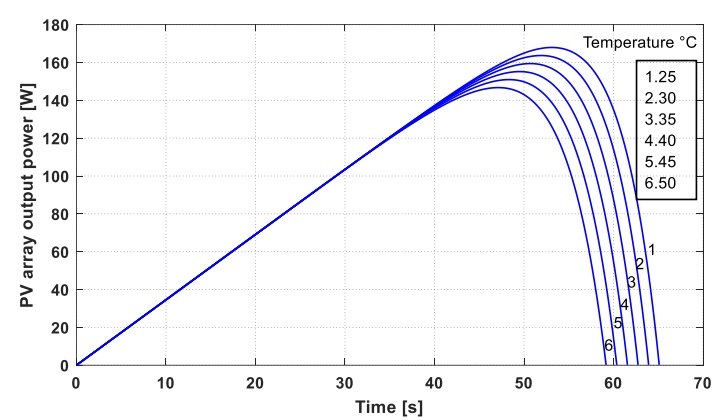

(b)

Figure. 3 The PV array's P-V curve of SM55 type with varying: (a) irradiance and (b) temperature

array voltage needs to be constantly balanced to pass the entire electricity.

\subsection{Modelling of grid-connected PV system:}

The grid-connected PV system dynamic model presented as follows:

$$
\begin{gathered}
\frac{d V_{p v}}{d t}=\frac{1}{C_{p v}}\left(I_{p v}-I_{L}\right) \\
\frac{d I_{L}}{d t}=\frac{1}{L}\left(V_{p v}-\left(1-u_{1}\right) V_{d c}\right)
\end{gathered}
$$

$$
\begin{gathered}
\frac{d V_{d c}}{d t}=\frac{1}{C_{d c}}\left(\left(1-u_{1}\right) I_{L}\right. \\
\left.+\left(1-2 u_{2}\right) I_{g}\right) \\
\frac{d I_{g}}{d t}=-\frac{1}{L_{g}}\left(R_{g} I_{g}+e_{g}\right. \\
\left.+\left(1-2 u_{2}\right) V_{d c}\right)
\end{gathered}
$$

The control suggested is based on the assumption that the boost converter's inductor and condenser are undefined; Thus with boost converters, regardless of parameter values, this regulation can act as an incentive to figure out how to solve uncertainty with an online calculation of unknown or variable parameters.

$$
\begin{gathered}
\theta_{1}=\frac{1}{C_{p v}} \\
\theta_{2}=\frac{1}{L}
\end{gathered}
$$

Thus, Eqs. (5) and (6) are now Eqs. (11) and (12):

$$
\begin{gathered}
\frac{d V_{p v}}{d t}=\theta_{1}\left(I_{p v}-I_{L}\right) \\
\frac{d I_{L}}{d t}=\theta_{2}\left(V_{p v}-\left(1-u_{1}\right) V_{d c}\right)
\end{gathered}
$$

\section{The proposed controller for MPPT: 4.1 Artificial Neural Network (ANN):}

ANNs are the best way to deal with nonlinear issues. Nowadays, they are widely employed for MPPT systems. They give better results in terms of performance compared to conventional algorithms. The neural feed-forward network (FNN) is called in this work. The ANN structure, as seen in Fig. 1, is the input, hidden, and output layers. Solar irradiation and temperature are the signals of input layer, and the PV model optimal voltage is the signal of the output layer. The training data was determined using MATLAB / Simulink to simulate the PV model. The input data to the ANN are reported as irradiance and temperature for each case. Also reported as ANN output data are the PV model optimal voltage according to each input 
combination. The network is used to calculate the optimum voltage of the PV model, when the PV model undergoes specific environmental parameters. The input signals are transmitted to the hidden layer whose activation function given in Eq. (15). The hidden layer neurons output activation is computed through the expression given in Eq. (16), referenced to [21]:

$$
\begin{gathered}
f_{h}(u)=\frac{1}{1+e^{-u}} \\
x=f_{h} \sum w_{h}[G T]^{T}+b_{h}
\end{gathered}
$$

The neurons strengths of hidden and output layers are, respectively, represented by the weight matrix $w_{h}$, $w_{o}$, and the bias $b_{h}, b_{o}$. The output neuron that uses the linear activation function can be represented as follows:

$$
f_{o}(x)=x
$$

The output layer neuron computes the voltage using the following relationship:

$$
\widehat{V}_{m p p}=f_{o}\left(w_{o} x+b_{o}\right)
$$

The ANN was trained off-line with the Bayesian regularization optimization technique using the Back-Propagation algorithm to reduce the meansquared error (MSE) that is computed by the following relationship:

$$
M S E=\frac{1}{n} \sum_{i=1}^{n}\left(V_{m p}(i)-\widehat{V}_{m p}(i)\right)^{2}
$$

Where $V_{m p}$ is the desired value of the $\mathrm{i}^{\text {th }}$ output neuron and $\widehat{V}_{m p}$ is the actual output of that neuron. Fig. 4 shows the best MSE is equal to $2.0641 \times 10^{-6}$, which conforms to the success of the ANN learning.

\subsection{The adaptive backstepping controller design:}

In this part, the adaptive nonlinear controller for $\mathrm{DC} / \mathrm{DC}$ boost converter is designed in the following steps [22]:

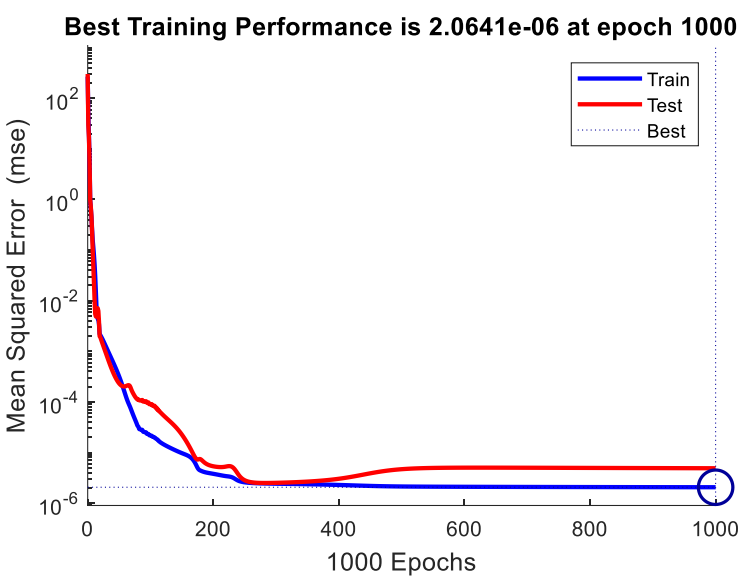

Figure. 4 ANN training performances

Step 1. Set the output voltage error of the converter:

$$
z_{1}=V_{p v}-V_{r e f}
$$

Where $\mathrm{V}(\mathrm{ref})$ is the ANN estimated voltage. Using Eqs. (13) and (20), As regards time, the derivative $\mathrm{z} 1$ may be obtained as:

$$
\dot{z}_{1}=\theta_{1}\left[i_{p v}-i_{L}\right]-\dot{V}_{r e f}
$$

The matrix structure of Eq. (21) can be written as follows if unknown parameters are presumed:

$$
\dot{z}_{1}=\hat{\theta}_{1} W_{1}-\dot{V}_{r e f}+\left(\theta_{1}-\hat{\theta}_{1}\right) W_{1}
$$

Where:

$$
W_{1}=\left[i_{p v}-i_{L}\right]
$$

Choose a lyapunov function as:

$$
V_{1}=\frac{1}{2} z_{1}^{2}+\Gamma_{11}^{-1}\left(\theta_{1}-\hat{\theta}_{1}\right)^{2}
$$

Where $\Gamma_{11}^{-1}$ is a positive coefficient and an adjustment parameter. $V_{1}$ Time's derivative is represented in the following way:

$$
\dot{V}_{1}=z_{1} \dot{z}_{1}+\Gamma_{11}^{-1}\left(\theta_{1}-\hat{\theta}_{1}\right)(-\dot{\hat{\theta}})
$$

Combining Eqs. (22) and (25) yields: 


$$
\begin{aligned}
& \dot{V}_{1}=z_{1}\left[\hat{\theta}_{1} W_{1}-\dot{V}_{r e f}\right]+\left(\theta_{1}-\right. \\
& \left.\hat{\theta}_{1}\right) \Gamma_{11}^{-1}\left[-\hat{\theta}+\Gamma_{11} z_{1} W_{1}\right]
\end{aligned}
$$

If in Eq. (26), it is assumed that:

$$
\hat{\theta}_{1} W_{1}-\dot{V}_{\text {ref }}=-c_{1} z_{1}
$$

and

$$
\left(\theta_{1}-\hat{\theta}_{1}\right)\left[-\dot{\hat{\theta}}+\Gamma_{11} z_{1} W_{1}\right]=0
$$

Step 2: As z1 is a virtual control, a second error variable $\mathrm{z} 2$ is specified in Eq. (29) respects to design the real control effort for the system:

$$
z_{2}=c_{1} z_{1}+\hat{\theta}_{1} W_{1}-\dot{V}_{r e f}
$$

Eqs. (22) and (29) combination gives:

$$
\dot{z}_{1}=z_{2}-c_{1} z_{1}+\left(\theta_{1}-\hat{\theta}_{1}\right) W_{1}
$$

Taking into consideration Eqs. (23) and (29) $z_{2}$ is rewritten as follows:

$$
z_{2}=\hat{\theta}_{1}\left[I_{p v}-I_{L}\right]-\dot{V}_{r e f}+c_{1} z_{1}
$$

$z_{2}$ time derivative with respect of time gives:

$$
\begin{gathered}
\dot{z}_{2}=\dot{\hat{\theta}}_{1}\left(I_{p v}-I_{L}\right)+\hat{\theta}_{1}\left(\dot{I}_{p v}-\dot{I}_{L}\right) \\
-\ddot{V}_{r e f}+c_{1} \dot{z}_{1}
\end{gathered}
$$

Using Eqs. (13), (14), and (22), the general form of Eq. (33) can be written as follows:

$$
\begin{aligned}
& \dot{z}_{2}=c_{1} z_{2}-c_{1}^{2} z_{1}+\left(\theta_{1}-\hat{\theta}_{1}\right)\left[I_{p v}-\right. \\
& \left.I_{L}\right] c_{1}+\dot{\hat{\theta}}_{1}\left(I_{p v}-I_{L}\right)+\hat{\theta}_{1} \dot{I}_{p v}- \\
& \hat{\theta}_{2}\left(\hat{\theta}_{1}\left(V_{p v}-(1-u) V_{d c}\right)\right)-\left(\theta_{2}-\right. \\
& \left.\hat{\theta}_{2}\right)\left(\hat{\theta}_{1}\left(V_{p v}-(1-u) V_{d c}\right)\right)-\ddot{V}_{r e f}
\end{aligned}
$$

Choose a second Lyapunov function as:

$$
V_{2}=V_{1}+\frac{1}{2} z_{2}^{2}+\Gamma_{22}^{-1}\left(\theta_{2}-\hat{\theta}_{2}\right)^{2}
$$

The time derivative respecting to time:

$$
\begin{aligned}
& \dot{V}_{2}=\dot{V}_{1}+z_{2} \dot{z}_{2}+\Gamma_{22}^{-1}\left(\theta_{2}-\right. \\
& \left.\hat{\theta}_{2}\right)\left(-\dot{\hat{\theta}}_{2}\right)
\end{aligned}
$$

Using Eq. (30) and Eq. (32), Eq. (35) can be changed to:

$$
\begin{aligned}
& \dot{V}_{2}=-c_{1} z_{1}^{2}+z_{2}\left[\left(1-c_{1}^{2}\right) z_{1}+c_{1} z_{2}+\right. \\
& \left.\hat{\theta}_{1} \dot{I}_{p v}+\dot{\hat{\theta}}_{1} W_{1}-\hat{\theta}_{2} W_{2}-\ddot{V}_{r e f}\right]+\left(\theta_{1}-\right. \\
& \left.\hat{\theta}_{1}\right) \Gamma_{11}^{-1}\left[-\dot{\hat{\theta}}_{1}+\Gamma_{11}\left(z_{1}+c_{1} z_{2}\right) W_{1}\right]- \\
& \left(\theta_{2}-\hat{\theta}_{2}\right) \Gamma_{22}^{-1}\left[\dot{\hat{\theta}}_{2}+\Gamma_{22} z_{2} W_{2}\right]
\end{aligned}
$$

Where:

$$
W_{2}=\hat{\theta}_{1}\left(V_{p v}-(1-u) V_{d c}\right)
$$

If in Eq. (36) we assume:

$$
\begin{aligned}
& {\left[c_{1} z_{2}+\left(1-c_{1}^{2}\right) z_{1}+\hat{\theta}_{1} \dot{I}_{p v}+\right.} \\
& \dot{\hat{\theta}}_{1}\left(I_{p v}-I_{L}\right)-\hat{\theta}_{2}\left(\hat { \theta } _ { 1 } \left(V_{p v}-(1-\right.\right. \\
& \left.\left.\left.u) V_{d c}\right)\right)-\ddot{V}_{r e f}\right]=-c_{2} z_{2}
\end{aligned}
$$

and

$$
-\dot{\hat{\theta}}_{1}+\Gamma_{11}\left(z_{1}+c_{1} z_{2}\right) W_{1}=0
$$

and

$$
\left[\dot{\hat{\theta}}_{2}+\Gamma_{22} z_{2} W_{2}\right]=0
$$

Then Eq. (36) is reduced to:

$$
\dot{V}_{2}=-c_{1} z_{1}^{2}-c_{2} z_{2}^{2}
$$

Using Eqs. (38), (39), and (40), the converter adaptive nonlinear controller $(\boldsymbol{u})$ and its parameters estimation laws $\left(\hat{\theta}_{i}\right.$ for $\left.\boldsymbol{i}=1,2\right)$ are as follows: 


$$
\begin{aligned}
& u=\frac{1}{\hat{\theta}_{1} \hat{\theta}_{2} V_{d c}}\left[\left(c_{2}+c_{1}\right) z_{2}+\right. \\
& \left(1-c_{1}^{2}\right) z_{1}+\hat{\theta}_{1} \dot{I}_{p v}+ \\
& \dot{\hat{\theta}}_{1}\left(I_{p v}-I_{L}\right)-\hat{\theta}_{2}\left(\hat { \theta } _ { 1 } \left(V_{p v}-\right.\right. \\
& \left.\left.\left.V_{d c}\right)\right)-\ddot{V}_{r e f}\right]
\end{aligned}
$$

And

$$
\dot{\hat{\theta}}_{1}=\Gamma_{11}\left(z_{1}+c_{1} z_{2}\right)\left(I_{p v}-I_{L}\right)
$$

And

$$
\dot{\hat{\theta}}_{2}=-\Gamma_{22} z_{2} \hat{\theta}_{1}\left(V_{p v}-(1-u) V_{d c}\right)
$$

\section{The grid current design:}

The primary function of the power factor is to synchronize the grid current and the grid voltage. The sliding mode controller is designed for this purpose. It enforces the current to follow the current defined by the relationship below [23]:

$$
i_{g}=\beta e_{g}
$$

Where $\beta$ is a positive parameter created by the PI controller that adjusts the DC bus voltage to monitor the desired voltage.

Assuming the grid voltage has sinusoidal form, the Eq. (44) will be rewritten as follows:

$$
i_{g}=\beta E \sqrt{2} \sin (w t)
$$

\subsection{The sliding mode controller design:}

The following steps can design the sliding mode controller:

Let us define the tracking error:

$$
\varepsilon=I_{g}-I_{g r e f}
$$

We suppose the sliding surface like this:

$$
S=\varepsilon
$$

The Eq. (47) time derivative gives:

$$
\dot{S}=\dot{\varepsilon}=\dot{I}_{g}-\dot{I}_{g r e f}
$$

Replacing Eq. (10) into Eq. (48) gives:

$$
\begin{gathered}
\dot{S}=-\frac{1}{L_{g}}\left(R_{g} I_{g}+e_{g}+\left(1-2 u_{2}\right) V_{d c}\right) \\
-\dot{I}_{g r e f}
\end{gathered}
$$

The sliding surface dynamic as follows:

$$
\dot{S}=-\Gamma \operatorname{sign}(S)
$$

Where $\Gamma$ is a positive parameter. The control stability can be guaranteed if $\dot{V}=-\Gamma|S|<0$, It can be conveniently verified that $\dot{V}$ is a negative definite function of $\mathrm{S}$ if the control input $u_{2}$ is chosen to be:

$$
\begin{aligned}
& u_{2}=\frac{L_{g}}{2 V_{d c}}\left[\frac{1}{L_{g}}\left(R_{g} I_{g}+e_{g}+V_{d c}\right)+\right. \\
& \left.\dot{I}_{\text {gref }}-\Gamma \operatorname{sign}(S)\right]
\end{aligned}
$$

\subsection{DC link regulation:}

The goal is to establish a control law for the ratio $\beta$ given in Eq. (44) in the way that the DC voltage tracks a desired reference value. The PI controller is proposed as follows:

$$
\beta(t)=K_{p} \varepsilon_{d c}(t)+K_{i} \int \varepsilon_{d c}(t) d t
$$

Where:

$K_{p}, K_{i}$ : The positive parameters of the regulator.

$\varepsilon_{d c}(t)=V_{d c}(t)-V_{d c r e f}(t)$ : The error between the DC voltage the desired value. 


\section{Results of simulation and discussion:}

The proposed non-linear adaptive controller built above is tested in this section using Matlab/Simulink. The block scheme of the evolved adaptive controller architecture is shown in Fig. 5. The research scheme for fast changes in sunlight and temperature, as seen in Fig. 6, shall be evaluated. The system performed at 6 cases. Case 1 is $40^{\circ} \mathrm{C}, 700 \mathrm{~W} / \mathrm{m} 2$; case 2 is $40^{\circ} \mathrm{C}$, $800 \mathrm{~W} / \mathrm{m} 2$; case 3 is $25^{\circ} \mathrm{C}, 800 \mathrm{~W} / \mathrm{m} 2$; case 4 is $25^{\circ} \mathrm{C}$, $900 \mathrm{~W} / \mathrm{m} 2$; case 5 is $25^{\circ} \mathrm{C}$ and $1000 \mathrm{~W} / \mathrm{m} 2$; and case 6 is $30^{\circ} \mathrm{C}$ and $900 \mathrm{~W} / \mathrm{m}^{2}$. Table 2 illustrates the used parameters for the whole simulation.

To prove the proposed controller efficiency improvement under these operating conditions, it is compared with the backstepping sliding mode controller combined with the ANN (ANN-BSMC), the direct method which is the $\mathrm{P} \& \mathrm{O}$ algorithm, and the integral backstepping sliding mode controller combined with ANN(ANN-BISMC) presented respectively in [24,25,26]. Fig. 7 shows the PV model output voltage of the compared methods; it can be seen, each controller can track the optimum voltage for MPP successfully. As noticed from this figure, it takes time for the $\mathrm{P} \& \mathrm{O}$ approach to get the best performance. Moreover, the $\mathrm{P} \& \mathrm{O}$ method oscillates around the optimal value and loses the tracking because of the rapid changes in the irradiation and temperature. In stable conditions or with minor irradiation and temperature changes, the ANNBSMC controller tracks the optimum ANN value. However, an obvious dynamic tracking overshoot when rapid change occurs. In other way, the ANNBSMC cannot handle the rapid change of the environmental changes. Fig. 8 depicts the PV model output power for the compared methods (the proposed method, ANN-BSMC, ANN-BISMC and $\mathrm{P} \& \mathrm{O})$ under the atmospheric condition changes. As noticed in this comparison, the adaptive controller performs better than other methods in all cases. Table 3 summarizes the performances of each controller. Comparing the MPPT speed of the methods, as observed in Fig. 8 the proposed methods reach the MPP at $1.4 \times 10-4 \mathrm{~s}$, the ANN-BSMC controller at $3.482 \times 10-3 \mathrm{~s}$, the ANN-BISMC controller at $3.434 \times 10-3 \mathrm{~s}$, and the $\mathrm{P} \& \mathrm{O}$ at $0.56 \mathrm{~s}$. These results reveal that the proposed method is the fastest to reach MPP. This method shows low oscillation rate; this

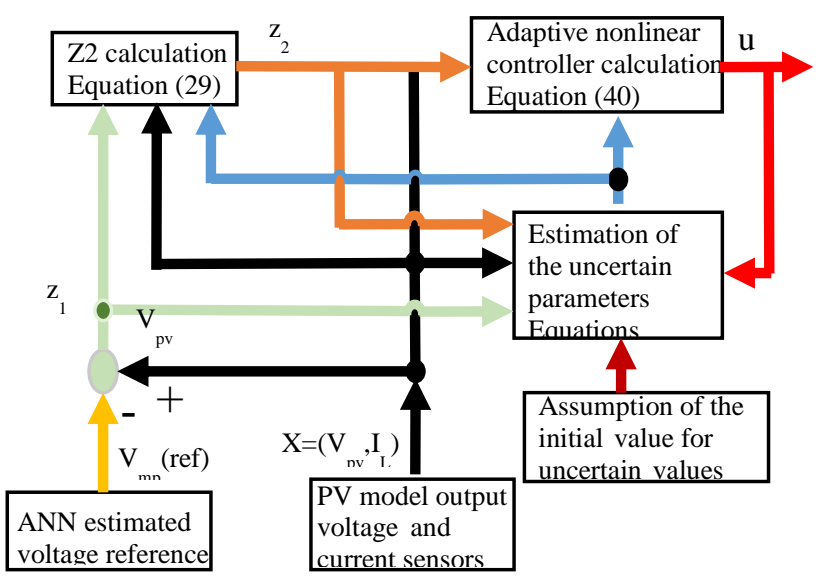

Figure. 5 The irradiation and temperature changes
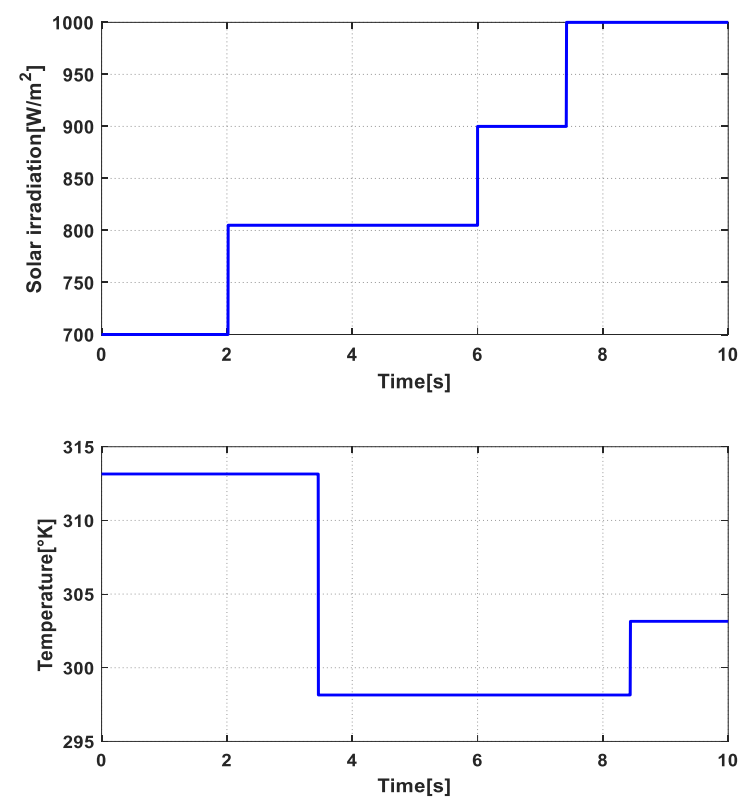

Figure. 6 The proposed controller design scheme

Table 2. The main used parameters for the simulation.

\begin{tabular}{|l|c|}
\hline Parameters' name & \multicolumn{1}{|c|}{ Values } \\
\hline The boost parameters & $\begin{array}{c}C_{p v}=440 \mu F, C_{d c}= \\
4700 \mu F, L=0.01 m H\end{array}$ \\
\hline $\begin{array}{l}\text { The adaptive } \\
\text { backstepping controller } \\
\text { parameters }\end{array}$ & $\begin{array}{c}c_{1}=9.3891 \times 10^{4}, \\
c_{2}=9.1026 \times 10^{4}, \\
\Gamma_{11}=3.1520 \times 10^{-16} \\
\Gamma_{22}=6.4015 \times 10^{-16}\end{array}$ \\
\hline $\begin{array}{l}\text { The grid parameters } \\
L_{g}=470 \mu F, R_{g}=470 \mu F, \\
e_{g}=470 \mu F\end{array}$ \\
\hline $\begin{array}{l}\text { The inverter controller } \\
\text { parameters }\end{array}$ & $\begin{array}{c}\Gamma=200 \\
\text { The PI controller } \\
\text { parameters }\end{array}$ \\
\hline
\end{tabular}




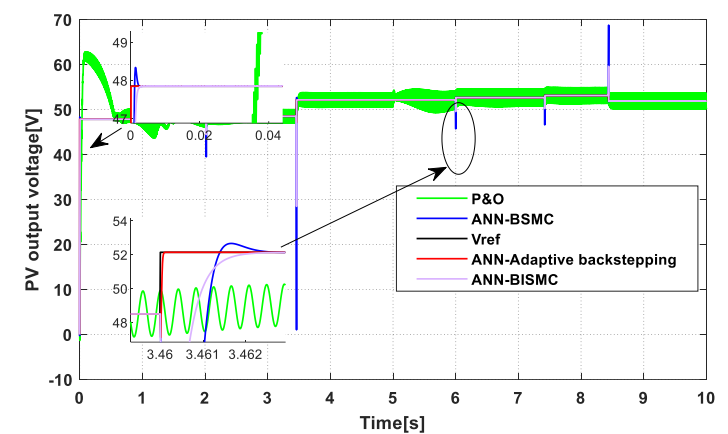

Figure. 8 The output voltage of the proposed controller compared to ANN-BSMC and $\mathrm{P} \& \mathrm{O}$

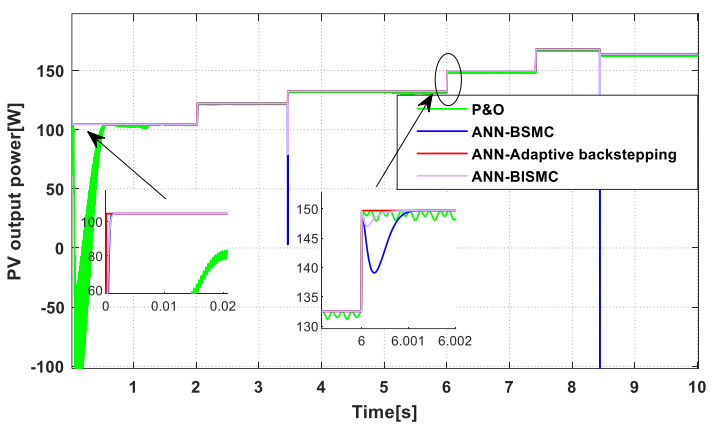

Figure. 8 The output power of the proposed controller compared to ANN-BSMC and $\mathrm{P} \& \mathrm{O}$

ensures low power loss. In Fig. 9, it is noticed that the duty cycle of the proposed method immediately reaches its optimal value with every change in the environmental condition. The suggested controller is more robust and fast over a wide range of atmospheric changes.

In the alternative side, the SMC is evaluated to control the inverter output current. The objective of the last one is to enforce the output current to follow the PI control reference value. To verify this assumption, Fig. 10 gives the input control. The input control is interpreted as a sine waveform with a major amplitude variation because of the reference current fluctuation. Fig. 11 presents the proposed control's sliding surface. This later oscillates around zero, thus converging the variable to its desired value is ensured. Fig. 12 demonstrates the grid current and voltage. It is noticed that the current and the voltage are in the same shape and phase. Therefore, the unity power factor is guaranteed. In addition, Fig. 13 shows the grid current pursuing its reference signal perfectly, which proves the accuracy of the SMC. Moreover, Fig. 14 depicts the DC link voltage reference. It is seen that the DC bus voltage follows the proposed

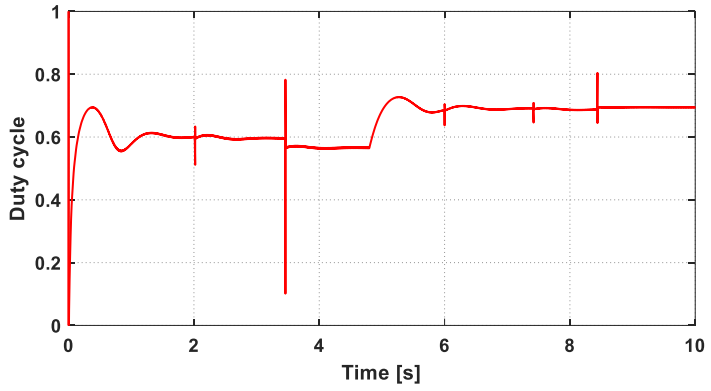

Figure. 10 The boost control signal.

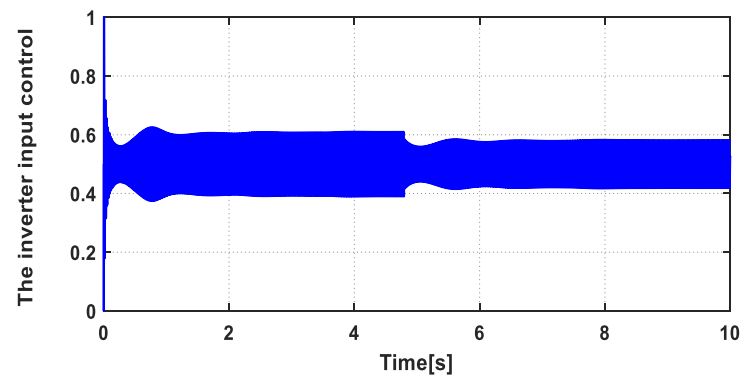

Figure. 9 The inverter control signal

reference during the environmental changes with small overtaking compared to other methods. The suggested approach can be inferred that the DC link speed was improved.

\section{Conclusion:}

In this research paper, a new adaptive backstepping controller enhances the PV system's MPPT. This controller is applied to the DC/DC boost converter to achieve the PV model optimum voltage regardless of the weather conditions. The ANN provides the control reference whereas the adaptive backstepping control is proposed to regulate this reference voltage by acting on the duty cycle of the boost converter. The study of the control stability is provided using the Lyapunov method. This adaptive controller allows the system to adapt itself when there is uncertainty in the converter's parameters (inductance $\mathrm{L}$, capacitor $\mathrm{C}$ ). The results are conducted under Matlab/Simulink.

To demonstrate the controller robustness, a comparison with the $\mathrm{P} \& \mathrm{O}$ and the ANN-BSMC and ANN-BISMC is made. Along the simulation results, the adaptive controller shows better improvement in the maximum power point tracking. It is observed that the suggested controller could track the reference voltage without steady state error and the overshoot is eliminated. Furthermore, the controller takes only $1.4 \times 10^{-4} \mathrm{~s}$ to reach the maximum operating point, which is faster than other methods, which suffer from overshoot and oscillation around the MPP. The 
Table 3. Compared controllers' performances

\begin{tabular}{|c|c|c|c|c|c|c|}
\hline & Case 1 & Case 2 & Case 3 & Case 4 & Case 5 & Case 6 \\
\hline \multicolumn{7}{|l|}{ Convergence time (s) } \\
\hline Proposed method & 0.00014 & 2.02 & 3.46 & 6 & 7.42 & 8.44 \\
\hline ANN-BSMC & 0.00382 & 2.03 & 3.464 & 6.00375 & 7.4239 & 8.443 \\
\hline $\mathrm{P} \& \mathrm{O}$ & 0.56 & 2.06 & 3.48 & 6.052 & 7.45 & 8.457 \\
\hline ANN-BISMC & 0.00343 & 2.023 & 3.463 & 6.0031 & 7.423 & 8.448 \\
\hline \multicolumn{7}{|l|}{ Efficiency (\%) } \\
\hline Proposed method & 99.96 & 99.87 & 99.93 & 99.99 & 99.99 & 99.98 \\
\hline ANN-BSMC & 99.90 & 99.81 & 99.91 & 99.93 & 99.94 & 99.96 \\
\hline $\mathrm{P} \& \mathrm{O}$ & 99.23 & 99.75 & 99.69 & 99.76 & 99.69 & 99.72 \\
\hline ANN-BISMC & 99.94 & 99.80 & 99.92 & 99.94 & 99.98 & 99.97 \\
\hline \multicolumn{7}{|l|}{ Number of oscillations } \\
\hline Proposed method & & & \multicolumn{4}{|c|}{ Neglected } \\
\hline ANN-BSMC & & & \multicolumn{4}{|c|}{ Neglected } \\
\hline ANN-BISMC & & & \multicolumn{4}{|c|}{ Neglected } \\
\hline $\mathrm{P} \& \mathrm{O}$ & & & \multicolumn{4}{|l|}{ High } \\
\hline
\end{tabular}

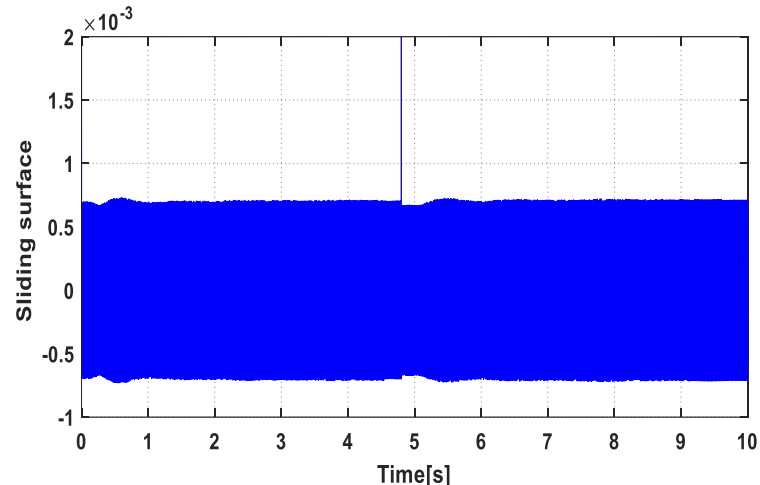

Figure. 11 The sliding surface for the inverter control law

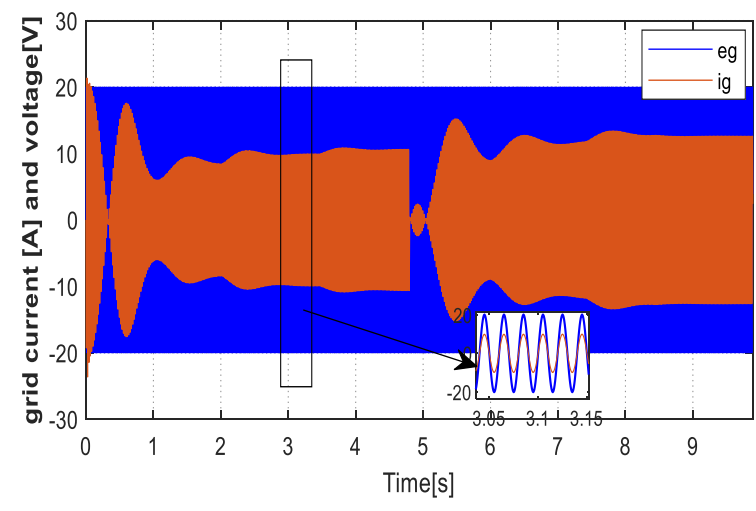

Figure. 12 Grid current and voltage

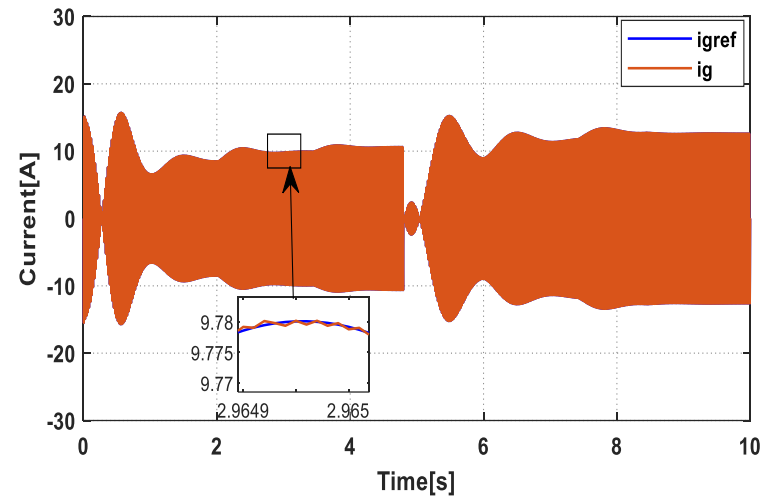

Figure. 13 Grid current

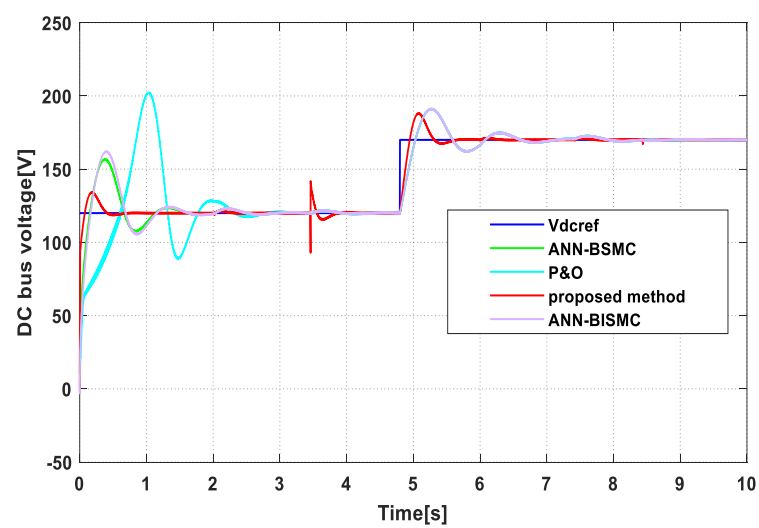

Figure. 11 DC link voltage. 
efficiency of the proposed method has an efficiency of $99 \%$. The output power is injected into the gridthrough a single-phase inverter. The proposed SMC of this inverter is validated in the simulation stage.

Moreover, the DC link voltage tracks the given reference regardless of any change in temperature and solar irradiation.

To conclude, the reliability of the adaptive backstepping system has been shown to control the boost converter and obtain full power. Through a numerical simulation, the results were compared.

\section{Conflicts of Interest}

The authors declare no conflict of interest.

\section{Author Contributions}

Rafika El Idrissi, as the corresponding author, has designed the proposed controller method for MPPT. Also, she has modelled the proposed system using Matlab/Simulink environment. Ahmad Abbou has supervised the written paper and providing the necessary data. Mohcine Mokhlis has contributed to the writing and the paper organization. All authors approved the final version.

\section{References}

[1] M. Mokhlis, M. Ferfra, Abbou.A, and Elidrissi.R, "Robust Control for Photovoltaic System Under Partial Shading Effect Using the SEPIC Converter", Int. J. Renew. Energy Res., Vol. 9, No. 2, 2019.

[2] Y. Chaibi, M. Salhi, and A. El-Jouni, "Sliding mode controllers for standalone PV systems: Modeling and approach of control", Int. J. Photoenergy, Vol. 2019, No. March, 2019.

[3] H. Bouzakri, and A. Abbou, "Mono-axial solar tracker with equatorial mount, for an improved model of a photovoltaic panel", Int. J. Renew. Energy Res., Vol. 10, No. 2, pp. 578-590, 2020.

[4] R. E. Idrissi, A. Abbou, M. Mohcine, and M.Salimi, "A comparative study of MPPT controllers for photovoltaic pumping system", in The 9th International Renewable Energy Congress (IREC 2018), 2018.

[5] S. M. Fatemi, M.S.Shadlu, and A.Talebkhah, "Comparison of three-point $\mathrm{P} \& \mathrm{O}$ and hill climbing methods for maximum power point tracking in PV systems", In: Proc. of 10th International Power Electronics, Drive Systems and Technologies Conference
(PEDSTC), 2019, pp. 764--768.

[6] M. Abdel-Salam, M. T. El-Mohandes, and M. El-Ghazaly, "An Efficient Tracking of MPP in PV Systems Using a Newly-Formulated P\&OMPPT Method Under Varying Irradiation Levels", J. Electr. Eng. Technol., Vol. 15, No. 1, pp. 501-513, 2020.

[7] A. Harrag and S. Messalti, "PSO-based SMC variable step size P\&O MPPT controller for PV systems under fast changing atmospheric conditions", Int. J. Numer. Model. Electron. Networks, Devices Fields, Vol. 32, No. 5, 2019.

[8] L. Shang, H. Guo, and W. Zhu, "An improved MPPT control strategy based on incremental conductance algorithm", Prot. Control Mod. Power Syst., Vol. 5, No. 1, 2020.

[9] X. Li, H. Wen, Y. Hu, and L. Jiang, "A novel beta parameter based fuzzy-logic controller for photovoltaic MPPT application", Renew. Energy, Vol. 130, pp. 416-427, 2019.

[10] U. Yilmaz, A. Kircay, and S. Borekci, "PV system fuzzy logic MPPT method and PI control as a charge controller", Renewable and Sustainable Energy Reviews, Vol. 81. Elsevier Ltd, pp. 994-1001, 2018.

[11] L. P. N. Jyothy, and M. R. Sindhu, "An Artificial Neural Network based MPPT Algorithm for Solar PV System", In: Proc. of the 4th International Conference on Electrical Energy Systems, ICEES 2018, pp. 375-380, 2018.

[12] S. Kumar Roy, S. Hussain, and M. A. Bazaz, "Implementation of MPPT technique for solar PV system using ANN", In: Proc. of 2017 Recent Developments in Control, Automation and Power Engineering, RDCAPE 2017, pp. 338-342, 2018.

[13] S. Messalti, A. Harrag, and A. Loukriz, "A new variable step size neural networks MPPT controller: Review, simulation and hardware implementation", Renewable and Sustainable Energy Reviews, Vol. 68. Elsevier Ltd, pp. 221-233, 2017.

[14] F. M. De Oliveira, S. A. Oliveira Da Silva, F. R. Durand, L. P. Sampaio, V. D. Bacon, and L. B. G. Campanhol, "Grid-tied photovoltaic system based on PSO MPPT technique with active power line conditioning", IET, Vol. 9, No. 6, pp. 1180-1191, 2016.

[15] A. Kihal, F. Krim, A. Laib, B. Talbi, and H. Afghoul, "An improved MPPT scheme employing adaptive integral derivative sliding mode control for photovoltaic systems under fast irradiation changes", ISA Trans., Vol. 87, No. July 2019, pp. 297-306, 2019. 
[16] M. A. Elgendy, B. Zahawi, and D. J. Atkinson, "Assessment of perturb and observe MPPT algorithm implementation techniques for PV pumping applications", IEEE Trans. Sustain. Energy, Vol. 3, No. 1, pp. 21-33, 2012.

[17] E. I. Rafika, A. Abbou, S. Rhaili, and M. Salimi, "Maximum power point tracking of photovoltaic systems using backstepping controller", In: Proc. of 2017 International Conference on Engineering and Technology, ICET 2017, 2018, Vol. 2018-January, pp. 1-6, 2018.

[18] M. Mokhlis, M. Ferfra, and R. El Idrissi, "High gain observer-based control for grid-connected pv system under partial shading effect", International Journal of Intelligent Engineering and Systems, Vol. 13, No. 2, pp. 161-181, 2020.

[19] H. El Fadil and F. Giri, "Nonlinear Adaptive Control for MPPT in Photovoltaic Systems", IFAC Proc. Vol., Vol. 42, No. 9, 2009.

[20] M. Salimi, J. Soltani, and G. A. Markadeh, "A novel method on adaptive backstepping control of buck choppers", In: Proc. of 2011 2nd Power Electronics, Drive Systems and Technologies Conference, 2011.

[21] M. Kermadi and E. M. Berkouk, "Arti fi cial intelligence-based maximum power point tracking controllers for Photovoltaic systems : Comparative study", Renew. Sustain. Energy Rev., Vol. 69, No. June, pp. 369-386, 2017, 2015.

[22] M. Salimi and A. Zakipour, "Direct voltage regulation of DC-DC buck converter in a wide range of operation using adaptive input-output linearization", IEEJ Trans. Electr. Electron. Eng., Vol. 10, No. 1, pp. 85-91, 2015.

[23] M. Guisser, E. Abdelmounim, M. Aboulfatah, and A. EL-Jouni, "Nonlinear Observer-Based Control for Grid Connected Photovoltaic System", IOSR J. Electr. Electron. Eng., Vol. 9, No. 5, pp. 40-52, 2014.

[24] K. Boudaraia, H. Mahmoudi, and A. Abbou, "MPPT Design Using Artificial Neural Network and Backstepping Sliding Mode Approach for Photovoltaic System under Various Weather Conditions", International Journal of Intelligent Engineering and Systems, Vol. 12, No. 6, pp. 177-186, 2019.

[25] A. I. M. Ali, M. A. Sayed, and E. E. M. Mohamed, "Modified efficient perturb and observe maximum power point tracking technique for grid-tied PV system", Int. J. Electr. Power Energy Syst., Vol. 99, pp. 192202, 2018.
[26] R. El Idrissi, A. Abbou, and M. Mokhlis, "Backstepping Integral Sliding Mode Control Method for Maximum Power Point Tracking for Optimization of PV System Operation Based on High-Gain Observer", International Journal of Intelligent Engineering and Systems, Vol. 13, No. 5, pp. 133-144, 2020. 